\title{
Self-directed Noticing for Defossilissation: Three Case Studies
}

\author{
FRANCES BOETTINGER \\ JUNGHYE PARK \\ IVOR TIMMIS* \\ Leeds Metropolitan University
}

Received: 9 June 2010 / Accepted: 30 July 2010

\begin{abstract}
This article discusses three case studies where researchers addressed specific aspects of their second language use which they perceived to be fossilised. The first case deals with a Korean researcher's perceived lack of progress in speaking skills in English, particularly in active vocabulary; the second case looks at an English researcher's problem with gender assignment and adjective agreement in German, while the third case looks at an English researcher's difficulties with French pronunciation. Each researcher devised a treatment for his/her particular problem independently and applied the treatment, for the most part, autonomously. We argue that this kind of approach has the potential to lead to defossilisation but, more importantly, we argue that it is an invaluable way of raising awareness of the range of cognitive and affective strategies that are available to the learner, and the importance of metacognitive knowledge and strategies in deploying these resources to best effect.
\end{abstract}

KEY WORDS:

Fossilisation; self-directed learning; metacognitive knowledge; task repetition; noticing

\section{RESUMEN}

En el presente artículo se analizan tres casos en los que los investigadores plantean aspectos concretos de usos de una segunda lengua percibidos como fosilizados. El primer caso se refiere a un investigador coreano en el que se detecta falta de mejora en la destreza oral del inglés, especialmente en relación con el vocabulario activo; el segundo caso analiza el problema de un investigador inglés en relación con la asignación de género y concordancia de adjetivos en alemán; el tercer caso analiza las dificultades de un investigador inglés en relación con la pronunciación del francés. Cada investigador diseñó un tratamiento para su problema y aplicó el tratamiento de manera mayoritariamente autónoma. Consideramos que este enfoque tiene la potencialidad de lograr la desfosilización, y sobre todo, que es una buena técnica para centrar la atención en las estrategias cognitivas y afectivas disponibles para el aprendiz así como para resaltar la importancia del conocimiento y estrategias metacognitivas al utilizar estos recursos para obtener la máxima eficacia.

PALABRAS CLAVE:

Fosilización, aprendizaje autónomo, conocimiento metacognitivo, repetición de tareas, atención.

*Address for correspondence: Dr. Ivor Timmis, Reader in English Language Teaching, Macaulay Hall, Headingley Campus, Leeds Metropolitan University, Leeds LS6 3QN. E-mail: i.timmis@leedsmet.ac.uk 


\section{INTRODUCTION}

Introspective studies, such as those reported in this paper, in which teachers or applied linguists reflect on their own learning are by no means unprecedented. A number of such studies (Golebiowska, 1985; Gower, 1999; Hyde, 2000; Jones, 1998; Lowe 1987; McDonough 2002; Ransdell, 1993) have been reported in the literature and the general tenor of the insights from these reports is that the experience of learning a language is salutary for teachers and often leads to interesting insights into their own learning preferences and strategies. As Hyde (2000: 265) notes, reflective studies of this kind "vary along a number of parameters, consisting of the setting, the type of teacher involved, whether the learning is individual or in a group, and the use of diaries or journals”. What distinguishes the three studies reported in this article is that they are focused on a specific aspect of the subjects' second language use which they perceived to be fossilised. The goal of the research reported here was, then, to establish whether the three subjects, all teachers of English, could combat fossilisation autonomously through the application of cognitive strategies to self-selected problems in three different domains: grammar, vocabulary and pronunciation. A further aim was to establish what the participants would gain from the process of addressing their selfselected problems. The paper begins with a discussion of the three main theoretical domains which inform the research: fossilisation, noticing and autonomy. The participants, their aims and the research methods are discussed in the methodology section. We then outline the procedure and results of each study in turn. This is followed by a discussion of the implications of the results of the three studies, and a conclusion which looks at the wider implications of this kind of research.

\section{THEORETICAL BACKGROUND}

\section{II.1 Fossilisation}

\section{II.1.1 Defining fossilization}

There are a number of definitions of the term “fossilisation”, coined by Selinker in 1972. Han (2004a: 13) describes fossilisation as the "phenomenon of non-progression of learning despite continuous exposure to input, adequate motivation to learn, and sufficient opportunity for practice”. Towell and Hawkins (1994) see fossilisation reflected in the retention of foreign accents, use of non-native grammatical structures and "non-native intuitions about the interpretations of certain types of sentence” (cited in Han 2004a: 13). Ellis (1994: 42) 
describes fossilisation as "the process by which non-target forms become fixed in interlanguage”. Although some SLA researchers, (Ellis; Vigil \& Oller cited in Han 2004a) also perceive use of correct forms as subject to fossilisation, most reserve the term fossilisation to refer exclusively to incorrect forms (Han 2004a:17). In our case, as Park's case of stagnation of active vocabulary is a form of non-progression of learning rather than persistence of error, we will follow Ellis, Vigil and Oller in seeing correct forms as potentially subject to fossilisation.

It should be acknowledged that the validity of the concept of fossilisation has been challenged. Tollefson and Firn (1983), for example, argued that the term fossilisation "should be reserved for something which has become rigid or fixed" like structures which have "ceased to be modified due to biological factors." Importantly for this article, such a literal interpretation would preclude the possibility of defossilisation. Tollefson and Firn (1983) go on to argue that "cessation of learning as the result of social, psychological and interactive variables" should not be considered permanent and therefore, cessation of interlanguage caused by these factors would be better termed "jellification". Since jellification is not necessarily an end-state, resumed learning could be called “dejelllification” (1983: 31). While we accept that learning never comes to an absolutely fixed end, the term fossilisation is generally recognized in the literature, and for our purposes it is important to note that the three learners in question perceived themselves as fossilised. For the purposes of this paper, we could define fossilisation as "a stabilized state in the learning process perceived as long term and problematic”.

\section{II.1.2 Properties of fossilization}

Han (2004b) describes five major properties of fossilisation. Amongst these properties, Han includes 'resistance to change'. This seems to us, however, to be a circular argument and to be already embedded in our definition of fossilisation. Similarly, while Han identifies interlanguage as a key property of fossilisation, we see it rather as a key concept underpinning fossilisation. We focus below, therefore, on three properties which are of clear relevance to the three studies in this paper: backsliding; occurrence in all areas of language; more frequent occurrence amongst adults.

A feature may be described as fossilised even if learners use it correctly on certain occasions and incorrectly at other times. Ellis (1994: 694) refers to this phenomenon as backsliding. Likewise, Bley-Vroman (cited in Han 2004a: 18) notes that learners may temporarily appear to improve but will end up reverting back to a stabilized imperfect level, particularly when under stress or involved in communicative activities with heavy mental processing demands. This is one reason why learners might be able to produce a form 
correctly in a discrete exercise, but not in a conversation where there is a need to process content and form at the same time. On the other hand, and this is of relevance to all three studies, it is also the reason why learners may be able to produce richer and/or more complex and/or more accurate language when repeating a task, as processing demands for content are reduced and more attention can be devoted to form.

All areas of language are susceptible to fossilization, though grammatical structures appear to be particularly resistant to change. This seems to apply particularly to those structures that are not common to both L1 and L2. An individual learner may not fossilise in all areas of his interlanguage system and will master some aspects of language learning better than others (Han 2004a: 7). Linguistic features often fossilise differentially within learners. For example, vocabulary may be less likely to fossilise than morphology (Fidler 2006: 402). In our case, all three learners report good progress in aspects of language other than the fossilised feature.

Although fossilisation is possible in both children and adults, adults are considered more susceptible to fossilisation. This relates to the critical period hypothesis which suggests that L2 learners can only acquire an L2 easily and achieve native speaker like competence up to a certain age after which "L2 acquisition becomes more difficult and is rarely entirely successful” (Ellis 1994: 699). It is significant for Timmis's study that pronunciation is regarded as an area of language particularly relevant for the critical age hypothesis. Researchers vary, however, in their opinions on the extent of the critical period.

\section{II.1.3 Causes of fossilization}

Han (2004a: 29), synthesising findings from research into fossilisation, created a table giving an overview of potential causes of fossilisation. The modified version below gives examples of each of the 4 main domains - environmental, cognitive, neurobiological and socioaffective - rather than the comprehensive list Han presents.

\begin{tabular}{|c|c|c|c|}
\hline & Domain & Sub-domain & Examples \\
\hline EXTERNAL & Environmental & & $\begin{array}{ll}\text { - } & \text { Absence of corrective feedback } \\
\text { - } & \text { Lack of input } \\
\text { - } & \text { Lack of instruction } \\
\text { - } & \text { Lack of communicative relevance } \\
\text { - } & \text { Quality of input } \\
\end{array}$ \\
\hline INTERNAL & Cognitive & $\begin{array}{l}\text { Knowledge } \\
\text { representation }\end{array}$ & $\begin{array}{ll}\text { - } & \text { L1 influence } \\
\text { - } & \text { Possession of a mature cognitive system } \\
\text { - } & \text { Learning inhibiting learning } \\
& \text { language faculty }\end{array}$ \\
\hline
\end{tabular}




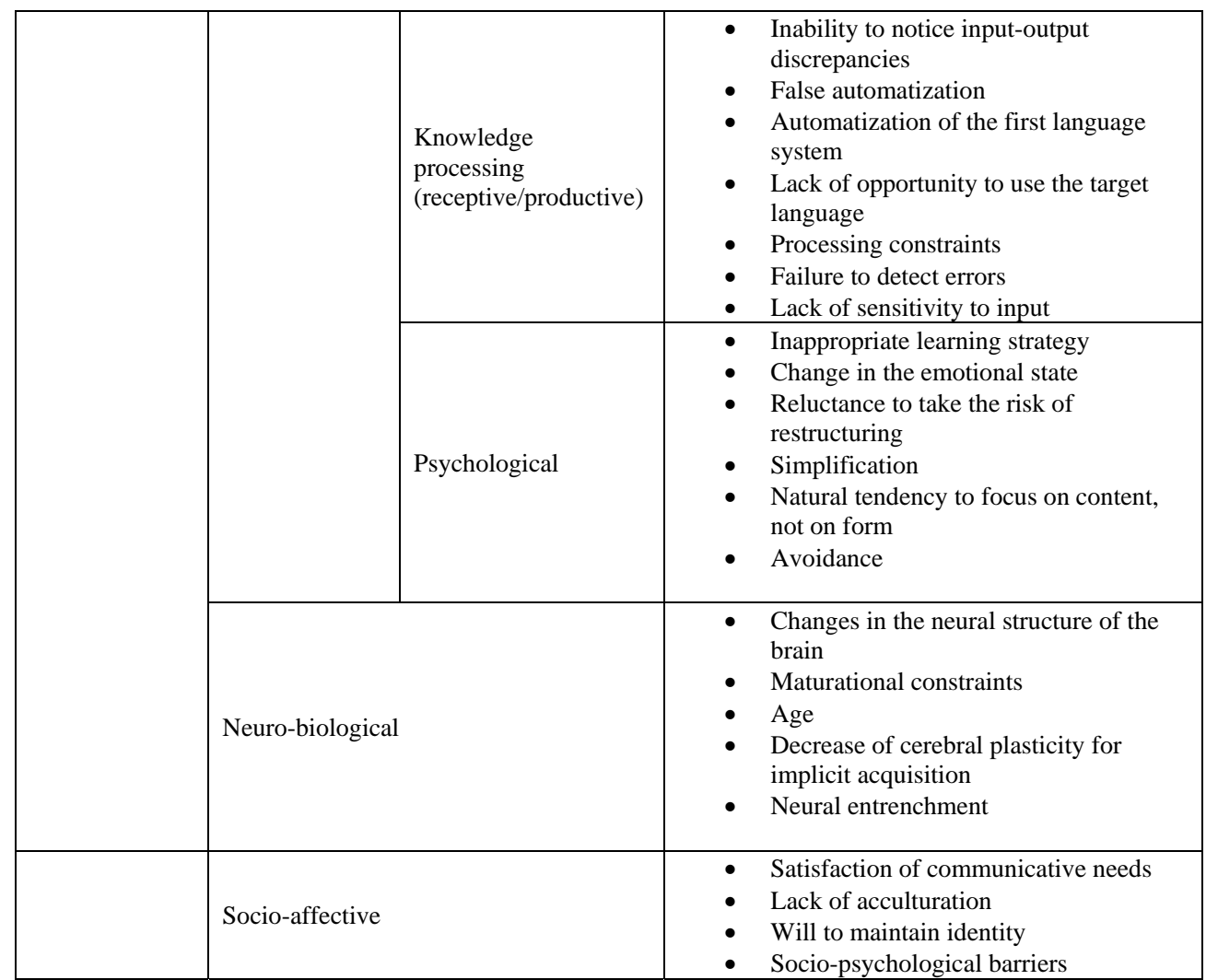

Table 1. Potential causes of fossilization (after Han 2004a)

The causes listed in Han's table show the complexity of fossilisation and suggest that a particular problem may not simply stem from one cause. Fossilisation in Han's (2004a: 43) view is internally determined "due to the constant functioning of maturational and native language constraints, yet it can be modulated (aggravated or alleviated) by environmental, social and psychological forces.” We elaborate below on frequently cited causes and those which seem particularly relevant to these three studies.

One cause frequently cited in this vast list is "satisfaction of communicative needs". In other words, once the learner is capable of communicating adequately with others, s/he may, consciously or subconsciously, lose the motivation to improve. "Lack of acculturation" is also widely recognized as a problem which affects language competence. Lack of integration into the target language community may result, for example, in disinterest in learning the L2 along with decreased exposure to input, particularly if the learner lives in an enclave of immigrants who speak the same L1 (Han 2004a: 34-35). 
Other potential causes are less concrete, for example "lack of sensitivity to input" which maintains, that adult L2 learners are incapable of fully acquiring the sound system of an additional language having acquired the sound system of their native language because of inevitable lose of phonetic sensitivity after learning the sounds of the first language (Han 2004a: 33). In addition, there may also be some overlap, particularly for neuro-biological causes, that could be related to aging, "changes in the neural structure" or "decrease of cerebral plasticity for implicit acquisition”, for example, which could also affect cognitive functions.

Han's list also includes a number of items which, from the standpoint of a practical language learner or teacher working towards defossilisation, could conceivably be influenced by teaching or learning methods. If we accept this view, then defossilisation becomes a possibility. Factors amenable to direct influence by teaching and learning methods are primarily of an environmental nature e.g. absence of corrective methods, lack of input or poor quality input, but could also include items such as inappropriate learning strategy and lack of acculturation which the teacher can influence more indirectly.

\section{II.2 Noticing}

A further theme that links all three studies is 'noticing'. Thornbury (1997), drawing on Schmidt and Frota (1986), argues that two types of noticing are necessary for acquisition to take place:

1. Learners must attend to linguistic features of the input that they are exposed to, without which input cannot become "intake".

2. Learners must "notice the gap" i.e. make comparisons between the current state of their developing linguistic system, as realized in their output, and the target language system, available as input.

Given that the three subjects were not primarily concerned with the acquisition of new linguistic features, it is the second type of noticing which is prominent in these studies. While Schmidt (1990: 131) does not conclude that noticing is sufficient for learning, he brought forth evidence of a "close connection between noticing and emergence in production”.

The role of consciousness in noticing may be a matter of some debate (Schmidt 1990), but these three studies were designed to promote explicit and conscious noticing and to focus on the participants' own output. As Lynch (2001: 125) notes, “although noticing is often defined in terms of attention to input, there is a growing body of research into learners' attention to their own output, notably by Merrill Swain and colleagues.” According to Swain's output hypothesis, output is as important as input to acquisition because "output 
pushes learners to process language more deeply than does input” (Swain 1995: 126). She suggests that one function of output in second language acquisition is noticing, which is promoted when "learners do not know how to say (or write) precisely the meaning they wish to convey." She also added that "under some circumstances, the activity of producing the target language may prompt second language learners to consciously recognize some of their linguistic problems; it may bring to their attention something they need to discover about their L2” (Swain 1993, cited in Swain 1995:126). Although a focus on output had obvious potential, it needed to be something more than just general output practice, as all three subjects had had many opportunities to speak. Three previous studies suggested a way of focusing more specifically on output.

Bygate (1996) analysed two performances by one student who was shown a video extract and then asked to retell the story. The exact task was repeated without warning three days later. Bygate then transcribed and analysed the two recorded speeches. His study found that task-repetition led to some improvement in fluency, accuracy and repertoire (i.e. range of language used). The repertoire aspect was particularly relevant to Park’s initial concerns about her range of active vocabulary. Bygate (1996) argued that when first carrying out the task, the learner would be initially more concerned with planning the content of the message, and under pressure of time, with finding sufficient resources to communicate the message. On the second occasion, on the other hand, the learner would be able to devote more attention to the form of the message.

Two further studies (Lynch 2001; Mennim 2003) shared the aim of encouraging learners to focus on form in their own output by getting the learners to transcribe and analyse their own recorded speech. Mennim (2003) set out to establish whether students could take advantage of a rehearsal of their final oral presentation in order to make improvements to their spoken output. The students in this study had a private rehearsal with him two weeks before their final presentation. The rehearsals were tape-recorded and students were asked to transcribe a five-minute segment. Students examined and corrected their transcripts before giving them to him. Mennim then provided further feedback on points that they had missed. He recorded the final presentation and compared the rehearsal transcripts with the final presentation transcripts. The final presentation showed improvements in production and grammar and in the organization of content. With this result, he argued that the transcription task and making corrections to the transcript encouraged students to focus their attention on form and improve their oral output.

Lynch (2001) also used transcription as a reflective noticing activity. In his study, pairs of adult learners of English for Academic Purposes transcribed their own performances of a routine classroom speaking task. Working collaboratively, they then discussed and edited the 
transcripts, making a large number of changes for the better. These edited transcripts were passed on to the teacher, who made further corrections and reformulations, and then discussed the changes with the learners. Lynch suggested that collaborative transcribing and editing can encourage learners to focus on form in their output in a relatively natural way.

Although he does not use specific research evidence, Thornbury (1997) argues the case for reconstruction tasks as a way of promoting noticing through output. Reconstruction tasks, which are of particular relevance to Boettinger's study, require the learner to reconstruct a given text, or elements of a given text, either with prompts or unaided. The rationale for reconstruction tasks is that: "In reconstructing a text, learners will deploy their available linguistic competence, which (depending, of course, on the choice of text) is likely to fall short of the model” (Thornbury 1997: 330). Most pertinently for our purposes, Thornbury (1997: 330) goes on to note that "the real benefit may be in the matching: the comparison by learners of their version with the model provides them with positive evidence of yet-to-beacquired features...”

\section{II.3 Autonomy}

Autonomy has become a fashionable word in recent years with a vast literature which cannot be summarized within the scope of this paper. We can, however, make a number of observations about learner autonomy which are of particular relevance to this study. Among the competing definitions of autonomy, the most apt for our purposes is that learner autonomy is 'essentially a matter of the learner's psychological relation to the process and content of learning...a capacity for detachment, critical reflection, decision-making and independent action' (Little 1991: 4). As Jones (1998) observes, there are degrees of autonomy. He defines full autonomy as solo instruction where the learners design the syllabus without specially prepared materials and without involvement either from a teacher or an institution. The three studies here meet most of these criteria, although all three subjects used an interlocutor and two had native speaker help with error correction. Jones (1998) summarises the theoretical benefits of autonomous learning, while acknowledging that there is little empirical evidence to support the theoretical case. Among the putative benefits outlined by Jones (1998) are greater intrinsic motivation, greater scope for personalisation of texts and tasks and a sense of self-empowerment through taking responsibility for one's own learning. Given that the participants in this research are at once teachers and learners, the notion of teacher autonomy is also relevant here, if teacher autonomy can be seen as the 'capacity for self-directed professional development’ (Benson 2006). 


\title{
III. RESEARCH METHODOLOGY
}

\section{III.1 The participants and their studies}

The profiles of the participants (at the time of the study) and the aims of their studies are summarised below:

\begin{abstract}
Park
Park is a Korean teacher of English. At the time of the study she was a student on an MA in English Language Teaching course in the UK. Park began the course with an IELTS level of 6.5 and her study was motivated by her perception that, despite having spent a number of months in the UK, her range of active vocabulary had become fossilised.
\end{abstract}

\section{Boettinger}

Boettinger is an American teacher of English resident in Germany. At the time of the study she had been living in Germany for around 15 years, although English remained the 'marital' language with her German husband. She reported a high level of functional fluency in German, but regarded gender assignment and adjective agreement as her Achilles heel. She was following an MA course in Language Education at the time of the study.

\section{Timmis}

Timmis is a tutor on an MA in English Language Teaching course at a UK university. He has a degree in French and at one time had a high degree of fluency. He reported, however, that even when at his most fluent, his English accent was easily recognisable and undermined his confidence. At the time of the study, he considered his French pronunciation to be fossilised or even in attrition.

From a methodological point of view, it is also important to understand the sequence of the studies and the relationship between the participants. Park conducted the initial study under the supervision of Timmis. Boettinger's project was also supervised by Timmis and she was able to draw on Park's work when conducting her own study. Timmis, in turn, was able to draw on both Park's and Boettinger's work. All three studies were in part inspired by the well known Schmidt-Frota (1986) experiment in which Schmidt documented his experiences in a five-week Portuguese course, keeping a journal and taping conversations between himself and a Portuguese interlocutor at monthly intervals.

\section{III.2 Research methods}

Although both Park and Boettinger used quantitative measures, the research is essentially qualitative: it is primarily concerned with the participants' perceptions of the strategies which were effective for them, and their perceptions of their success in addressing their respective problems. In the sense that each study involved a planned intervention as a response to a specific problem, and the evaluation of that intervention, each study could be said to fall 
under an action research paradigm. If one takes the broad definition of introspective methods outlined by Dörnyei (2007), which includes retrospective self-report, then introspection is clearly a key research method for all three studies. The reliability of retrospective self-report is often questioned on the grounds that memory is imperfect, but in these three studies, the participants had recordings and/or transcripts and/or quantitative measures to support their reflections. A more serious reservation we must acknowledge about the research methodology employed here is that small scale action research is by definition limited in its generalisability. This applies all the more so when the participants are not typical of the population to which the generalization may be applied. In this case, we must keep in mind that, while the three subjects are language learners, they are also experienced and well qualified language teachers and likely to have a higher degree of metacognitive awareness than the average learner.

\section{THE THREE STUDIES}

\section{IV.1 The causes of the fossilization problems}

Park was very unclear about the cause of her problem with active vocabulary. As a student resident in the UK and attending an MA in ELT course, Park was receiving a great deal of target language input, and was motivated to improve her English. On the face of it, the conditions for development were very favourable, but the problem remained. In this respect, it is interesting that DeKeyser (2007) notes that students on study abroad programmes, contrary to popular belief, may actually have restricted opportunities for output, input and feedback of the requisite quality to stimulate acquisition. Environmental factors were a plausible cause for Park's problems. In an interview with Timmis conducted for a different research project (Timmis 2008), lack of strategies emerged as another potential cause.

Boettinger analysed the causes of her problem with gender assignment and adjective endings in some depth and cited a number of potential factors (from Han's list) contributing to the problem. Language complexity was an obvious starting point. Studies of English native speakers learning German have revealed that even advanced learners of German have persistent difficulty with gender assignment (Rogers 1987; Tanner 2006). Furthermore,” acquisition of gender in German as L1 (as well as in other languages) and in German as L2 is generally thought to be acquired relatively late in the developmental sequence” (Rogers 1987: 70). Boettinger also felt that discontinuing formal instruction and devoting less focused attention to language improvement had contributed to her fossilisation. A further consequence of discontinuing formal instruction was that Boettinger received very little corrective feedback. The corrective feedback she did receive was largely from her husband, and she 
often regarded this as neither timely nor sensitive. In other words, an environmental factor was in conflict with a socioaffective factor. Boettinger also noted that, after becoming an English teacher 6 years prior to the study, her interactions in German had been largely limited to routine exchanges. As we noted above, DeKeyser (2007) has argued, living in the target environment does not automatically guarantee either quantity or, more importantly, quality of input or output.

In terms of Han's table of causes of fossilisation, Timmis sees his problems with French pronunciation as lying mainly in the socioaffective domain. Timmis has a strong sense of northern identity, and there is at least a folk linguistic theory that males from northern English industrial towns find French pronunciation rather effeminate and shy away from adopting it (consciously or subconsciously). In addition, he also has a stammer which he felt inhibited him in speaking French. Other potential causes perceived by Timmis are "lack of sensitivity to input” and age. Timmis considers that he does not have a good ear for accents and acknowledges that, as an adult learner, achieving a native-like accent is very difficult.

\section{IV.2 Procedures and results of the three studies}

\section{IV.2.1 Park's study}

Against the theoretical background discussed in section II, Park decided to conduct a miniexperiment which incorporated both task repetition and transcription of her own output. An interview was chosen as a task because it was a real-world task and a good way to generate the required data (spoken language) from natural conversation. Before the first interview, Timmis (her tutor) chose the topic and questions, and Park was only told the topic: "How does the MA course (ELT MD) help non-native students improve their English?” In the first interview, Park was asked questions about the chosen topic and expected to have the same questions again three days later. However, on the second occasion, Timmis, the interviewer, asked the questions slightly differently. In other words, while the topics remained the same, the questions were not identical and varied somewhat according to Park's answers. Therefore it was not the exact task repetition that Bygate (1996) had carried out, but more like task recycling: the format remained the same - an interview on the same topics - but the prompts differed.

The data was collected from the two interviews, in the form of transcriptions of the recordings. This was done by the subject, Park. The key difference between the first and second interview was that on the second occasion Park was familiar with the topic and the interviewer, which meant she had more time to think about the answers. Although, as noted above, the questions were slightly different between the two interviews, people would predict 
that generally a learner would perform better the second time. The data was divided into two as follows and analysed separately:

Data 1 - two transcripts from both interviews

Data 2 - selected from questions were identical in both interviews

More specifically Data 1 can be considered as the result of task recycling, whereas Data 2 can be as the result of task repetition.

Skehan noted (2001: 170) that, when measuring task performance, "in general, there is some consensus that measures are required in the three areas of complexity, accuracy and fluency. These three areas are theorised to have important independent functioning in oral performance.” The specific features to be analysed in this study are listed in Table 2.

\begin{tabular}{|c|c|}
\hline Accuracy & - Error \\
\hline \multirow{4}{*}{ Fluency } & - $\quad$ Speed (words per minute) \\
\hline & - Repetition \\
\hline & $\begin{array}{l}\text { - Repeating a word or phrase } \\
\text { - Self correction }\end{array}$ \\
\hline & - Vague language \\
\hline \multirow{3}{*}{ Complexity } & - Tokens (the total number of words) \\
\hline & - Types (the number of different words used) \\
\hline & - Type/token ratio \\
\hline
\end{tabular}

Table 2. Aspects for analysis

We look first at analysis based on Data 1(two transcripts from both interviews). It can also be considered as the result of task recycling.

\section{Accuracy}

Grammatical, lexical and overall errors were counted. Contrary to the expectation there was no improvement regarding errors (see Table 3). An interesting result was that the errors which Park made most in each performance were not those that she usually thought difficult. In the first interview Park didn't put's' at the end of plural words, while in the second one she forgot to put ' $\mathrm{s}$ ' at the end of the verb for the third person singular. Park reported that she would rarely, if ever, make those types of errors in written texts. In addition, on both occasions she repeated non-native collocations which came from Korean translation: feel difficulty $\left(1^{\text {st }}\right.$ interview), say their opinion ( $2^{\text {nd }}$ interview). 


\begin{tabular}{|l|l||l|}
\hline Accuracy & $\begin{array}{l}\text { 1st } \\
\text { interview }\end{array}$ & $\begin{array}{l}\text { 2nd } \\
\text { interview }\end{array}$ \\
\hline Error & 57 & 58 \\
\hline
\end{tabular}

Table 3. Analysis of Data 1: accuracy

\section{Complexity}

The total number of words (tokens) and the number of different words (types) were compared between the two performances. Type-token ratio shows the range of vocabulary and a higher score indicates less repetition. According to Table 4 , the $2^{\text {nd }}$ interview has a higher type-token ratio than the $1^{\text {st }}$, which means that Park used a wider range of vocabulary in the second interview.

\begin{tabular}{|c|l|l|}
\hline Complexity & $\begin{array}{l}\text { 1st } \\
\text { interview }\end{array}$ & $\begin{array}{l}\text { 2nd } \\
\text { interview }\end{array}$ \\
\hline$\bullet \quad$ Tokens & 1618 & 1438 \\
\hline$\bullet \quad$ Types & 347 & 344 \\
\hline$\bullet \quad$ Type/token ratio & $21 \%$ & $24 \%$ \\
\hline
\end{tabular}

Table 4. Analysis of Data 1: type/token ratio

\section{Fluency}

The amount and type of repetition, speed of production and use of fillers (e.g. um, ah) were calculated. Table 5 shows significant improvement in fluency: faster speech, less repetition and less use of fillers in the second interview. It was found that Park often repeated the same words or phrases several times in one sentence and she especially used "and then" a lot regardless of the meaning e.g. "um be because I have I have uh I have teaching experience but it wasn't that long so I had to find out uh the relation between my experience and then the theory or the things in class.”

Repeating the same word or phrases and using fillers can be a way of gaining time while you think about what to say next. Compared to the $1^{\text {st }}$ interview, the second time there was a sharp drop in repetition of the same words or phrases and also the use of vague language. However, the number of self corrections increased. It seems that on the first occasion Park paid more attention to producing appropriate content and gained some time to think through what she wanted to say by using repeated words and vague language. In 
contrast, on the second occasion, with the familiarity of the topic and questions, she was able to devote more attention to monitoring her output, which might have increased the number of instances of self correction. It is possible, therefore, that encountering a similar task led to the sharp drop in repetition of the words and the use of fillers, which in turn led to faster speech.

\begin{tabular}{|c|l|l|}
\hline Fluency & $\begin{array}{l}\text { 1st } \\
\text { interview }\end{array}$ & $\begin{array}{l}\text { 2nd } \\
\text { Interview }\end{array}$ \\
\hline$\bullet \quad$ Speed (w/m) & $111 / \mathrm{min}$ & $122 / \mathrm{min}$ \\
\hline$\bullet \quad$ Repetition & & \\
\hline $\begin{array}{l}\text {-Repeating a word } \\
\text { or phrase }\end{array}$ & 100 & 70 \\
\hline -Self correction & 9 & 11 \\
\hline$\quad$ Fillers & 124 & 110 \\
\hline
\end{tabular}

Table 5. Analysis of Data 1: fluency

We turn now to the analysis of Data, which came from questions common to both interviews and could be considered the result of task-repetition. It was also analysed in order to see if there was any difference from the results obtained from the analysis of Data1. The results looked similar; there were improvements in fluency and complexity, as seen in Table 6.

\begin{tabular}{|l|l|l|l|}
\hline \multirow{4}{*}{ Fluency } & & $\begin{array}{l}1 \text { ist } \\
\text { interview }\end{array}$ & $\begin{array}{l}2^{\text {nd }} \\
\text { interview }\end{array}$ \\
\cline { 2 - 5 } & $\bullet \quad$ Speed (w/m) & $100 /$ min & $107 /$ min \\
\cline { 2 - 5 } & - Repetition & & 28 \\
\cline { 2 - 5 } & -Self correction & 55 & 4 \\
\hline Complexity & $\bullet \quad$ Tokens & 621 & 580 \\
\cline { 2 - 5 } & $\bullet \quad$ Types & 192 & $34 \%$ \\
\cline { 2 - 5 } & $\bullet \quad$ Type/token ratio & $31 \%$ & $34 \%$ \\
\hline
\end{tabular}

Table 6. Analysis of Data 2: fluency and complexity

On the other hand, the data in Table 7 shows a noticeable fall in accuracy. Even though the questions were the same, more errors were made in the second interview. The use of fillers was the same on both occasions. It is notable that while the result of the first analysis 
showed that the number of fillers decreased on the second occasion, it remained the same for data 2 (Compare Table 7 with Table 5).

\begin{tabular}{|c|l|l|}
\hline & $\begin{array}{l}1 \text { st } \\
\text { interview }\end{array}$ & $\begin{array}{l}\text { 2nd } \\
\text { interview }\end{array}$ \\
\hline Accuracy & & \\
\hline$\quad$ Error & 20 & 28 \\
\hline Fluency & & \\
\hline$\bullet \quad$ Fillers & 45 & 45 \\
\hline
\end{tabular}

Table 7. Analysis of data 2: fluency and accuracy

Skehan (2001: 170) provides a possible explanation for this result with his argument that the three performance domains -accuracy, fluency and complexity- “...enter into competition with one another, with higher performance in one area seeming to detract from performance in others”. So, for example, greater accuracy may well be achieved at the expense of greater complexity, and vice versa. It seems that encountering the same questions led Park to improve fluency and at the same time to promote risk-taking by paying more attention to producing better answers. This is seen in the improved complexity. However, this improvement may have caused her to make more errors.

\section{IV.2.2 Boettinger's study}

In an attempt to further understand and remedy her fossilisation, Boettinger devised a research project which involved a number of different activities or strategies in two phases.

\section{Phase 1}

Boettinger selected topics for a presentation based on her interests and gave the presentation to a German native speaker, using notes rather than a script. Once the presentation had been recorded, the learner and tutor listened to the tape and reviewed language errors, with a particular focus on the target area of gender and adjective ending assignment.

A distinctive feature of Boettinger's approach was the use of what she termed "coaching dialogues” inspired by the idea of Voice Dialogues which have been applied, for example, as a management training technique to help solve complex issues (Sussens-Messerer 2007: 7779). Essentially, a coaching dialogue was a written internal dialogue between Boettinger as learner and Boettinger as coach e.g. 
Learner: Well, I really didn’t prepare very much for this. I think it would have been better if I had rehearsed it in my head.

Coach: Maybe. But it was more spontaneous and gave an indication of typical mistakes. Did you notice anything special?

Learner: Yes, a couple of times I used "In" with the date and a couple of times I caught myself when I was more concentrated. I know it’s wrong but I still say it anyway.

Subsequently, an indicative portion of each taped presentation was transcribed and the tapescript was reviewed and analyzed for errors.

\section{Phase 2}

Based on the findings from phase 1, Boettinger developed a remedial programme of exercises based on her own output to remedy specific errors. These activities included producing a written version of the oral presentation; reconstructing the presentation from an outline which included content words, dates and references, but not articles or adjective endings; gapped versions of the transcript based on the target grammar (and some other problematic areas for Boettinger). All three activities are essentially reconstruction tasks. Boettinger then repeated presentations of the topics on tape. The transcripts of the second presentation series were analyzed and compared to results of the first presentation series to determine if possible improvements relative to accuracy or fluency might indicate potential defossilisation. This was clearly a form of task repetition.

Overall fluency in Phase II improved significantly, there were few pauses in presenting the texts, pronunciation was clear and the learner did not make any errors with word order or word choice. The learner's fluency in Phase II was positively influenced because there were no interruptions by an interlocutor to break the learner's train of thought.

The following table shows that in comparison to Phase 1, errors related to genders and related articles and/or adjective endings declined overall by $8 \%$ although in regarding the statistics one should also consider that total utterances, and thus possibilities for making more errors, was considerable higher in Phase II (440 as opposed to 297 in Phase 1). It is also interesting that results throughout Phase II were more consistent, error percentage varying from 4-6\% whereby in Phase I, there range was between $9-18 \%$. 


\begin{tabular}{|llll|} 
& Total & & $\begin{array}{l}\text { Errors as a } \\
\% \\
\text { of utterances }\end{array}$ \\
PHASE 1 & utterances & Errors & \\
Rembrandt & 57 & 10 & $18 \%$ \\
Hatschepsut & 56 & 5 & $9 \%$ \\
Adenauer & 66 & 9 & $14 \%$ \\
Elvis & 67 & 7 & $10 \%$ \\
Louis & 51 & 9 & $18 \%$ \\
TOTAL & 297 & 40 & $13 \%$ \\
& & & \\
PHASE II & & & \\
Rembrandt & 74 & 4 & $5 \%$ \\
Hatschepsut & 99 & 4 & $4 \%$ \\
Adenauer & 96 & 6 & $6 \%$ \\
Elvis & 89 & 4 & $4 \%$ \\
Louis & 82 & 4 & $5 \%$ \\
TOTAL & 440 & 22 & $5 \%$ \\
\hline
\end{tabular}

Table 8. Percentage of errors related to genders and adjective endings

\section{IV.2.3 Timmis's study}

As Timmis was well acquainted with Park's and Boettinger's studies, he was able to draw explicitly on their approaches in formulating his own remedy. As a result, Timmis's account subsumes part of the conclusion to the article, since what struck Timmis most about Park's and Boettinger's accounts was that both. Timmis’s approach consisted of three phases:

\section{Phase 1}

Timmis regards himself as a highly analytical learner, and initially used a self-study tape to revise French vowel sounds and distinctive consonants such as the uvular fricative ' $r$ '. This practice was highly mechanical, involving repetition of individual sounds, repetition of words containing the target sounds and discrimination between sounds e.g. the vowel sounds in "vous" and "tu”. From an affective point of view, Timmis was very conscious at this stage that he did now want to expose his pronunciation to external appraisal, but he felt even at this stage that he had identified a key problem: his vowel sounds were simply too long in many cases, and he needed to make more "facial effort" to produce the vowel in "tu" and distinguish it from the vowel in "tout".

\section{Phase 2}

Timmis, drawing on Boettinger's idea of choosing a topic of personal interest, wrote a text about his experiences during a year abroad in France, a topic he can talk about with enthusiasm and feeling. He asked a French colleague to record the text. He then listened to the text and recorded several versions of his own for comparison purposes. In this phase, Timmis also made use of "slow-down technology" (Campbell et al 2004) for the native speaker 
version of the text. This technology allows a reduced speed version of the text to be recorded without tonal distortion. This version led Timmis to specific insights e.g. he was producing exaggerated stress on the first syllable of 'Colmar' compared to the native speaker version, and producing a schwa sound at the end of "inoubliable”. Timmis was pleasantly surprised that, after his preparatory work, his accent didn’t sound as bad as he feared.

\section{Phase 3}

Timmis, drawing on Park’s rationale, asked a French friend to interview him about his experience to see if his pronunciation would hold up under the pressure of real-time conversation. The questions were not prepared, so there was a certain degree of unpredictability, although the preparatory work in composing the text would clearly be of value.

Somewhat paradoxically, Timmis found that focusing on the technicalities of pronunciation made him a little less self-conscious about speaking French. The interview was instructive. When he listened to the recording, it was very clear that his pronunciation was most convincing where he had lifted whole phrases from the prepared text: without the need to work out the vocabulary and grammar, he had the processing space to focus on the pronunciation, which doesn't come naturally and requires concentration. Progress in pronunciation is difficult to quantify and, having identified the causes of his fossilisation as being primarily socioaffective, Timmis was content with a positive self assessment of his progress and a compliment from his interlocutor.

\section{DISCUSSION}

The research set out to establish whether fossilisation could be combated through the autonomous application of cognitive strategies and all three subjects reported a degree of success. Park reported that quantitative results showed some improvements in her fluency and complexity which suggest that task repetition or task recycling can potentially contribute to improving learners' oral output. Boettinger concluded that that partial defossilisation of grammatical features may be possible through self-directed noticing and execution of targeted remedial activities involving repetition. Timmis reported that defossilisation of his pronunciation was possible to a certain extent through repetition and comparison procedures, but this work would need to go hand in hand with a more general rehabilitation of his French if it were to have any lasting effect. Boettinger and Timmis both commented that they were surprised by the role that traditional techniques such as memorisation and repetition played in 
their studies. As Lowe (1987) has noted, it is not unusual for teachers in the position of language learners to adopt the traditional techniques they shy away from in their own teaching. While this by no means constitutes a call for a wholesale rehabilitation of "traditional" techniques, it does seem to suggest that we need to be more discriminating in abandoning techniques which may still have value for specific purposes. Cumulatively, the three studies suggest that self-directed noticing has the potential to achieve at least partial defossilisation. We need, however, to keep in mind our earlier caveat about the limitations of the study in terms of generalisability.

In terms of the autonomous aspect, Park reported a significant increase in her motivation to address the targeted area while Park and Timmis both reported a feeling of selfempowerment through taking responsibility for their own learning. We noted above that the notion of autonomy can be extended to include teacher autonomy. In this respect, it is interesting that Boettinger noted that she had become more aware of her own learners' possible learning processes and had even incorporated specific activities from her study recording and transcription - in her own classes.

An interesting but unexpected finding of the research was the role of affective factors. While Park's approach was highly cognitive in its use of transcription, error analysis and calculations of fluency rate and lexical density, it is arguable that the most important outcome was affective: a sense of empowerment. Boettinger's approach began as highly cognitive with rule revision, transcription and error analysis (though an affective element was present from the outset with the choice of motivating topics). As the research progressed, the affective element became more prominent with the use of coaching dialogues (and even attempts at self-hypnosis). Timmis was reluctant to expose his pronunciation to appraisal in the early stages and the choice of an affectively significant topic was important for him in overcoming this barrier.

\section{CONCLUSION}

In conclusion, the three studies suggest that self-directed noticing has the potential to combat perceived fossilisation through the application of both cognitive and affective strategies. The optimum balance of cognitive and affective strategies is likely to depend both on the nature of the problem involved and the characteristics of the individual learner. However, the research was also concerned with what the participants would gain from the process of self-directed fossilisation. In this sense, we would argue that, individually and cumulatively, the three studies demonstrate the importance of what Wenden (1998) terms "metacognitive 
knowledge" in combating perceived fossilisation. Wenden identifies three main domains of metacognitive knowledge: person knowledge, task knowledge, and strategic knowledge. Aspects of each of these domains are highly relevant to the above studies. Person knowledge includes knowledge of cognitive and affective variables which affect second language learning, "knowledge about...proficiency in a given area" and "self-efficacy beliefs about their ability to mobilize and manage the resources necessary to learn and to sustain the effort" (Wenden 1998: 518). Task knowledge, evident in the remedies chosen by each of the three subjects, “includes information about a task's demands, i.e. how to learn in general, how to go about doing a particular task, and the knowledge and skills needed to do so" (Wenden 1998: 518). Strategic knowledge "refers to general knowledge about what strategies are, why they are useful, and specific knowledge about when and how to use them” (Wenden 1998: 519). This latter domain is particularly interesting as Park. commented that she was aware of many different strategies to improve her English, but initially used none as she felt overwhelmed by the variety. Similarly, Timmis, though a highly experienced teacher of English, took a long time to devise his remedial approach.

Wenden (1998) also argues that metacognitive knowledge is a characteristic common to "expert learners" and that it plays a crucial role in self-regulation in underpinning the planning, monitoring and evaluation of progress i.e. metacognitive strategies. It is very clear, then, that metacognitive knowledge and metacognitive strategies are central to language learning in general, not just to autonomous defossilisation. What we argue, here, however, is that autonomous defossilisation requires a highly concentrated focus on metacognitive knowledge and metacognitive strategies, and as such is a valuable tool for raising teachers' awareness of these important domains. This awareness should then equip teachers to develop autonomy and reflection in their learners. We would suggest that short, self-directed learning projects, whether focused on defossilisation or not, might usefully be incorporated in teacher education courses.

\section{REFERENCES}

Bley-Vroman, R. (1989).What is the Logical Problem of Foreign Language Learning? In S. Gass and J. Schachter (Eds.), Linguistic perspectives on second language acquisition (pp. 41-68). Cambridge: Cambridge University Press.

Benson, P. (2006) Autonomy in language teaching and learning. Language Teaching, 40, 21-40.

Campbell, D., Meinardi, M., Richardson, B., Coyle, E., Donnellan, O., Leung, P.K., MacDonaill, C., Jung, E., Pritchard, C., (2004) DIT-CALL - naturally speaking, but slow. Speak Out!, 32, 2835.

DeKeyser, R. (2007). Study Abroad as Foreign Language Practice. In R. M. DeKeyser (Ed.), Practice in a second language: perspectives from applied linguistics and cognitive psychology (pp. 208-225). Cambridge: Cambridge University Press.

Dörnyei, Z. (2007). Research methods in applied linguistics. Oxford: Oxford University Press. 
Ellis, R. (1985). Understanding second language acquisition. Oxford: Oxford University Press.

Ellis, R. (1994). The study of second language acquisition. Oxford: Oxford University. Press.

Fidler, A. (2006). Reconceptualizing fossilisation in second language acquisition: a review. Second Language Research, 22(3), 398-411.

Golebiowska, A. (1985). Once a teacher, always a teacher. ELT Journal, 39(4), 274-278.

Gower, R. (1999). Doing as we would be done by. Modern English Teacher, 8(4), 7-15.

Han, Z.H. (2004a). Fossilization in adult second language acquisition. Clevedon, UK: Multilingual Matters.

Han, Z.H. (2004b). Fossilisation: five central issues. International Journal of Applied Linguistics, 14(2), 212-242.

Harder, P. (1980). Discourse as self-expression: on the reduced personality of the second language learner. Applied Linguistics, 1(3), 262-270.

Hyde, B. (2000). Teachers as learners: beyond language learning. ELT Journal, 54(3), 265-273.

Jones, F. (1998). Self-instruction and success: a learner-profile study. Applied Linguistics, 19(3), 378406.

Lardiere, D. (1998). Case and tense in the 'fossilised' steady state. Second Language Research, 14:1/1

Little, D. (1991). Learner autonomy 1: Definitions, issues and problems. Dublin: Authentik.

Lowe, T. (1987). An experiment in role reversal: teachers as language learners. ELT Journal, 41(2), 89-96.

Lynch, T. (2001). Seeing what they meant: transcribing as a route to noticing. ELT Journal, 55(2), 124-132.

Lynch T. (2007).Learning from the transcripts of an oral communication task. ELT Journal, 61(4), 311-320.

McDonough, J. (2002).The teacher as language learner: worlds of difference. ELT Journal, 56(4), 404-411.

MacWhinney B. (2006).Emergent Fossilisation. In Z-H Han \& T. Odlin (Eds.), Studies of fossilisation in second language acquisition (pp.134-156). Clevedon, UK: Multilingual Matters.

Mennim, P. (2003). Rehearsed oral L2 output and reactive focus on form. ELT Journal,57(2), 130138.

Odlin, T., Alonso R. and C. Alonso-Vazquez (2006).Fossilisation in L2 and L3. In Z-H Han, \& T. Odlin (Eds.), Studies of fossilisation in second language acquisition (pp. 83-99). Clevedon, UK: Multilingual Matters.

Ransdell, D. R. (1993). Creative writing is Greek to me: the continuing education of a language teacher. ELT Journal, 47(1), 40-45.

Rogers, M. (1987).Learners' difficulties with grammatical gender in German as a foreign language. Applied Linguistics, 8(1), 48-74.

Schmidt, R. (1990).The role of consciousness in second language learning. Applied Linguistics, 11(2), 129-158.

Schmidt, R. and Frota, S.N. (1986). Developing Conversational Ability in a Foreign Language: A Case Study of an Adult Learner of Portuguese. In Day, R., (Ed.). Talking to learn: conversation in SLA (pp. 237-326). Rowley, MA: Newbury House.

Segalowitz, N. (2003). Automaticity and Second Languages. In Doughty C. and Long M. (Eds.), The handbook of second language acquisition (pp. 382-408). Blackwell Publishing.

Selinker, L. (1972).Interlanguage. International Review of Applied Linguistics, 10(2), 209-31.

Selinker, L. (2006). Afterword: Fossilisation 'or 'Does your Mind Mind? In Han, Z-H and Odlin, T. (Eds.), Studies of Fossilisation in Second Language Acquisition (pp. 201-210). Clevedon, UK: Multilingual Matters.

Skehan, P. (2001). Tasks and Language Performance Assessment. In M. Bygate, P. Skehan, \& M. Swain (Eds.), Researching pedagogic tasks: second language learning, teaching and testing (pp. 167-185). Harlow, Essex: Addison Wesley Longman.

Sussens-Messerer, V. (2007). Managing ourselves. Business Spotlight, 6(7), 77-79.

Swain, M. (1995). Three functions of output in second language learning. In G. Cook and B. Seidlhofer (Eds.), Principles and practice in applied linguistics: studies in honour of H.G. Widdowson (pp. 125-144). Oxford: Oxford University Press. 
Tanner, D. (2006).Agreeing that agreement isn't the problem: selective fossilisation in L2. [Internet] Available from: http: students.washington.edu/dstanner/Genderpaper.pdf [Accessed 16 June 2007].

Thornbury, S. (1997).Reformulation and reconstruction: tasks that promote 'noticing'. ELT Journal, 51(4), 326-35.

Timmis, I. (2008) DIY EAP: Is it really possible? IATEFL Research, 22, 14-17.

Tollefson J. and Firn, J. (1983).Fossilisation in second language acquisition: an inter-model view. RELC Journal ,14(19), 19-34.

Vigil, N. and J. Oller (1976). Rule fossilisation: a tentative model. Language. Learning, 22(5), 281295.

Wenden, A. (1998).Metacognitive knowledge and language learning. Applied Linguistics, 19(4), 515537. 